\title{
Persistent left superior vena cava with almost complete anomalous pulmonary venous conection and atrial septal defect mimicking Eisenmenger's syndrome in an adult symptomatic female patient
}

\author{
Marko Boban', Vesna Pehar Pejčinović', Krešimir Štambuk², Viktor Peršić1*, Davorka Žagar ${ }^{1}$, \\ Robert Bernat ${ }^{2}$ \\ ${ }^{1}$ Thalassotherapija Opatija, Opatija, Croatia \\ ${ }^{2}$ Clinic for Cardiovascular Diseases Magdalena, Krapinske Toplice, Croatia
}

Partial anomalous pulmonary venous connection (PAPVC) is a rare congenital cardiac anomaly in which a few of the pulmonary veins connect to the right atrium or its tributaries instead of the left atrium. The PAPVC to the superior vena cava (SVC) occurs in about $10 \%$ to $15 \%$ of all patients with atrial septal defect (ASD). Approximately 10\% have a secundum ASD associated with this anomaly.

We report a 54-year old female patient with an acute inferior myocardial infarction with ST segment elevation (STEMI). After cardiac catheterization and echocardiography we found significantly elevated pulmonary artery pressure, secundum ASD and high suspicion of Eisenmenger's syndrome. According to multislice computed tomography (MSCT) and magnetic resonance imaging (MRI), it was diagnosed an PAPVC connected through persistent left superior vena cava into the innominate vein and right atrium, associated with secundum ASD. Invasive measurements also confirmed partial anomalous pulmonary venous connection to the PLSVC, that drains to right atrium, and of lower oxygen saturation between the atria at the secundum defect, providing oxygenated blood to the left atrium only from the right atrium.
The development of complications depends on how many pulmonary veins return to the right atrium. The special feature of the clinical presentation and hemodynamic characteristics of 54 year old female patient with PAPVC suffered myocardial infarction and reversal of shunt. Due to confirmation that pulmonary hypertension was vasodilator responsive, excluding the Eisenmenger's syndrome patient was referred to cardiac surgery in experienced center to evaluate possibilities for total surgical repair of the TAVC, especially outweighing the risk and benefits.

KEYWORDS: total anomalous venous connection, persistent left superior vena cava, Eisenmenger's syndrome, acute myocardial infarction.

\section{Received: $20^{\text {th }}$ Mar 2013}

*Address for correspondence: Thalassotherapija Opatija, Maršala Tita 188/1, HR51410 Opatija, Croatia.

Phone +385-51-202-724

E-mail: viktor.persic@ ri.t-com.hr

\section{Literature}

1. Gustafson RA, Warden HE, Murray GF, et al. Partial anomalous pulmonary venous connection to the right side of the heart. J Thorac Cardiovasc Surg. 1989;98:861-6. 2. Povoski SP, Khabiri H. Persistent left superior vena cava: review of the literature, clinical implications, and relevance of alterations in thoracic central venous anatomy as pertaining to the general principles of central venous access device placement and venography in cancer patients. World J Surg Oncol. 2011 Dec 28;9:173.

3. Keane JF, Fyler DC. Total anomalous pulmonary venous return. In: Nadas' Pediatric Cardiology, 2nd, Keane JF, Lock JE, Fyler DC (Eds), Saunders Elsevier, Philadelphia 2006. p.773.

4. Michielon G, Di Donato RM, Pasquini L, Giannico S, Brancaccio G, Mazzera E, et al. Total anomalous pulmonary venous connection: long-term appraisal with evolving technical solutions. Eur J Cardiothorac Surg. 2002;22(2):184-91. 